\title{
Evaluation of Different Imaging Modalities for Axillary Lymph Node Staging in Breast Cancer Patients to Provide A Personalized and Optimized Therapy Algorithm
}

\section{Joachim Diessner ( $\square$ diessner_J@ukw.de )}

University of Wurzburg: Julius-Maximilians-Universitat Wurzburg https://orcid.org/0000-0001-55634885

\section{Laura Anders}

University Hospital Wurzburg: Universitatsklinikum Wurzburg

\section{Saskia Herbert}

University Hospital Wurzburg: Universitatsklinikum Wurzburg

\section{Matthias Kiesel}

University Hospital Wurzburg: Universitatsklinikum Wurzburg

\section{Thorsten Bley}

University of Wurzburg: Julius-Maximilians-Universitat Wurzburg

\section{Tanja Schlaiss}

Universitätsklinikum Würzburg: Universitatsklinikum Wurzburg

\section{Stephanie Sauer}

University of Wurzburg: Julius-Maximilians-Universitat Wurzburg

\section{Achim Wöckel}

Universitätsklinikum Würzburg: Universitatsklinikum Wurzburg

\section{Catharina Bartmann}

University of Wurzburg: Julius-Maximilians-Universitat Wurzburg

\section{Research Article}

Keywords: breast cancer imaging, positive nodal status, cross-sectional imaging, conventional imaging, post-neoadjuvant therapies, neoadjuvant therapies

Posted Date: August 5th, 2021

DOl: https://doi.org/10.21203/rs.3.rs-710245/v1

License: (1) This work is licensed under a Creative Commons Attribution 4.0 International License. Read Full License 
Page $2 / 20$ 


\section{Abstract}

Purpose The prognostic importance of lymph node infiltration in breast cancer patients before and after neoadjuvant therapy has increased significantly in recent years. For that reason, the reliable detection of tumor-infiltrated axillary lymph nodes at the time of diagnosis plays a decisive role in further therapy. We therefore focused on the sensitivity of different pretherapeutic imaging modalities (sonography, mammography, computed tomography [CT] and magnetic resonance imaging [MRI]) in nodal positive breast cancer patients and aimed to find out whether cross-sectional imaging techniques (MRI, CT) could improve sensitivity for pretherapeutic axillary staging compared to conventional imaging such as mammography and sonography.

Methods Breast cancer patients with tumor-infiltrated axillary lymph nodes between 2014 and 2020 having a surgery for breast cancer were included in the study.

Results All included 382 breast cancer patients had received conventional imaging, while $52.61 \%$ of the patients had received cross-sectional imaging. The sensitivity of the combination of all imaging modalities was $68.89 \%$. The combination of MRI and CT showed $63.83 \%$ and the combination of sonography and mammography showed $36.11 \%$ sensitivity.

Conclusion We could demonstrate that cross-sectional imaging can improve the sensitivity of the detection of tumor-infiltrated axillary lymph nodes in breast cancer patients. Considering the increasing importance of neoadjuvant and post-neoadjuvant therapeutic algorithms, the reliable detection of tumorinfiltrated lymph nodes gains increasing importance.

Only the safe detection of tumor-infiltrated lymph nodes at the time of diagnosis enables the evaluation of the response to neoadjuvant therapy and thereby allows access to prognosis-improving postneoadjuvant therapies.

\section{Introduction}

The axillary lymph node status is considered to be one of the most important prognostic factors regarding the long-term survival of breast cancer (BC) patients [1, 2]. Moreover, the knowledge whether lymph nodes are tumor-infiltrated or not is essential, since nodal involvement has decisive therapeutic consequences such as axillary lymph node dissection (ALND), axillary radiotherapy and neoadjuvant or adjuvant systemic chemotherapy [3].

To provide individualized therapeutic options and optimized therapy algorithms for BC patients it is crucial to perform an exact pretherapeutic evaluation of the nodal status of the axilla. Ultrasound is considered to be the imaging modality of choice for evaluating the axillary lymph node status in BC patients and is usually combined with mammography in the conventional imaging setting [4]. The sensitivity of mammography for detection of nodal involvement is stated below $25.00 \%$ [5]. The sensitivity of ultrasound for axillary staging revealing nodal metastases ranges between $15.00 \%$ and 
$85.00 \%$ depending on the literature $[4,6]$. CT is not used by default for axillary staging, but can be valuable for detecting infiltrated mammary and supraclavicular lymph nodes [7]. Furthermore, CT imaging is able to prove nodal involvement on basis of morphological features such as irregular cortical thickening or the absence of internal fat density $[8,9]$. The diagnostic performance of the MRI for detecting axillary metastases seems promising with a sensitivity ranging from $35.00 \%$ up to over $80.00 \%$ in systematic reviews [10-12].

Over the past decades, different management strategies have emerged in axillary lymph node surgery favoring less invasive procedures. To that effect ALND has been replaced by sentinel lymph node biopsy (SNB) in early stages of BC [13]. Especially after the publication of the ACOSOG Z0011 and AMAROS clinical trials which have shown that even in patients with nodal involvement (1 or 2 positive sentinel nodes) - who meet certain criteria - there seems to be no additional benefit of the ALND regarding clinical outcome $[14,15]$. In patients with clinically nodal negative (cN0) disease the excision of the sentinel node is considered to be the standard procedure for the evaluation of the axilla with identification rates above $90.00 \%$ and false negative rates (FNR) $<10.00 \%$ even after NAC [16]. However, in patients with nodepositive disease who receive NAC and convert into clinically nodal negative disease (ycN0), identification rates of infiltrated lymph nodes by SNB were lower (89.00\%) and false negative rates were higher (13.00\%). Therefore, the sole procedure of SNB is not recommended for these high-risk patients and new surgical strategies for the staging of the axilla are needed $[17,18]$.

An improvement of the axillary evaluation in patients with initially nodal positive disease and NAC was accomplished by implementing the targeted axillary dissection (TAD). Caudle and coworkers showed a FNR of $2.00 \%$ when removing the sentinel lymph node as well as the clipped lymph node after NAC [19]. If the axillary lymph node is detected prior to the start of neoadjuvant chemotherapy, histologically proven and consecutively clipped, targeted axillary dissection is an option to contribute to the de-escalation of axillary surgery and save patients from axillary dissection which is associated with high morbidity [20]. The guidelines of the AGO (Arbeitsgemeinschaft Gynäkologische Onkologie) breast committee have already implemented the option of performing a TAD in clinically node positive patients who converted into ycNO after neoadjuvant systemic therapy [17]. If we do not distinguish safely between $\mathrm{cN}+$ and cNO patients in the pretherapeutic setting, we miss the opportunity to offer individualized multidisciplinary therapies like the TAD to patients with nodal involvement. Moreover, the overlook of a tumor-infiltrated lymph node in the neoadjuvant setting entails not only the risk of denying the use of TAD but also the possible identification of lymph nodes, which are still positive after the neoadjuvant therapy. This in turn could prevent the group of BC patients, who did not achieve complete remission and who are at high risk of negative clinical outcome, from receiving a post-NAC. The positive clinical effect of post-neoadjuvant therapies has been proven for the Her2 positive and the triple negative BC [21, 22]. For hormone receptor positive breast cancer, there are promising results [23].

The aim of this study was to evaluate the sensitivity of different pretherapeutic imaging modalities (sonography, mammography, CT and MRI) in nodal positive BC patients and to find out if there is a further benefit of using cross-sectional imaging (MRI, CT) for pretherapeutic axillary staging compared to 
conventional imaging such as mammography and sonography [4]. Since the utilization of neoadjuvant chemotherapy is advancing and due to the fact that the diagnostic validity of the axillary staging is less conclusive after the administration of NAC, we chose a retrospective study design including only nodal positive patients receiving adjuvant chemotherapy.

\section{Methods}

\section{Study population and data collection}

The study population consisted of BC patients having received surgery for BC (breast-conserving surgery or mastectomy) as well as lymph node surgeries (sentinel lymph node biopsy and/or axillary lymph node dissection) in the gynaecological clinic of the Wuerzburg University Hospital between 2014 and 2020. Inclusion criteria were a pathological positive lymph node status, no neoadjuvant therapy and a data record being complete for evaluation. The following data were collected from the electronic or paper medical data records: age, sex, menopausal status, body mass index (BMI), pathology report (histological type of BC, pathological tumor as well as lymph node status using the TNM system, oestrogen receptor, progesterone receptor and Her2 receptor, $\mathrm{Ki}-67$ and grading) and the results of the lymph node status and possible metastases in the different imaging modalities [sonography, mammography, MRI, CT (thorax and abdomen)]. Surrogate definition was used to determine BC subtypes considering the hormone receptors and the Her2 receptor as well as $\mathrm{Ki}-67$ according to the German guideline for $\mathrm{BC}$ [24]: luminal A (HR positive, Her2 negative, Ki- $67<25 \%$ ), luminal B Her2 negative (HR positive, Her2 negative, Ki-67 $\geq 25 \%$ ), luminal B Her2 positive (HR positive, Her2 positive), Her2 overexpressing (HR negative, Her2 positive) and triple negative (HR negative, Her2 negative).

\section{Statistical analysis}

The software IBM SPSS Statistics 26 (IBM Deutschland GmbH, 71137 Ehningen) was used to collect data, create tables and to perform statistical analysis. Data are presented in numbers and percent (\%). Spearman rho test was performed to test correlation of the different imaging modalities. Sensitivity was calculated as the proportion (in percent) of correctly identified positive lymph nodes via imaging. Chisquare-tests compared possible differences in the number of positive and negative detected lymph nodes of the imaging modalities. Multiple binary logistic regression analyses were performed to detect variables influencing the detection of positive lymph nodes. $p$ values lower than 0.05 were considered significant.

\section{Results}

\section{Basic characteristics of the study population}

The data of 382 node positive BC patients with adjuvant treatment between 2014 and 2020 were enrolled in this study. This corresponds to a percentage of $21.90 \%$ of all BC patients treated in our department of 
gynaecological oncology during this period. Basic characteristics of the study population are summarized in table 1.

Most BC patients were suffering from invasive carcinoma of no special type (304 patients; $80.85 \%$ ), while 57 patients $(15.16 \%)$ had an invasive lobular breast cancer. Other BC entities were found in 15 patients (3.99\%). Further details of stage and subtype of BC are shown in table 2.

\section{Different imaging modalities}

With regard to the imaging, 379 patients (99.21\%) received a sonography and 363 (95.03\%) a mammography. Altogether, all patients (382 patients) had a conventional imaging (sonography and/or mammography). While MRI was performed in 106 patients (27.75\%), a CT was performed in 142 cases (37.17\%). During the investigated period $52.61 \%$ of the patients had a cross-sectional imaging (MRI and/or CT). There was a trend of a higher ratio of cross-sectional imaging in relation to conventional imaging (sonography and/or mammography) (table 3).

Bivariate correlation tests revealed a significant correlation of the results of the different imaging modalities. (table 4)

\section{Sensitivity}

Comparing the different imaging modalities, sonography had a sensitivity of $34.56 \%$ to detect a positive lymph node status. The sensitivity of the mammography was considerably lower (14.60\%). A higher sensitivity was analyzed for MRI with $41.51 \%$ and $51.40 \%$ for CT. Altogether, the sensitivity of the crosssectional imaging (MRI and/or CT) was higher than the sensitivity of the conventional imaging (sonography and/or mammography) (50.25\% versus $37.17 \%)$.

By combination of all imaging modalities, the sensitivity was $68.89 \%$. Slightly lower values could be achieved for the combination of sonography, MRI and CT (68.09\%) and for the combination of mammography, MRI and CT (65.91\%). The sensitivity of the combination of both cross-sectional imaging modalities (CT and MRI) was $63.83 \%$. Table 5 shows the sensitivity of the imaging modalities and their combinations in a descending order. Generally, there were significant differences between positive and negative lymph node detection in the chi-square-testing by comparing the different imaging modalities and their combinations. Only in a few cases the results were not statistically significant, although the sensitivity varied strongly. (mammography vs. all imaging $p=0.053$; mammography vs. sonography, MRI and CT $p=0.053$; mammography vs. MRI and CT $p=0.201$ ).

\section{Factors influencing lymph node detection}


The main factors influencing the detection of positive lymph nodes significantly in at least one of all imaging modalities were the tumor size (odds ratio 1.93 [1.43-2.59], $\mathrm{p}=0.000$ ), the nodal status (odds ratio (1.66 [1.17-2.36], $p=0.005$ ) and the tumor grading (odd ratio 2.52 [1.49-4.30], $p=0.001$ ). Table 6 demonstrates the relevant variables of the cross-sectional imaging, the conventional imaging and each imaging modality alone. Table 7 illustrates the increasing sensitivity with increasing tumor size for sonography, mammography and CT. MRI however shows almost constant sensitivity values independently of the tumor size. Except for tumor stage pT4, there were significant differences between conventional imaging (sonography and/or mammography) and cross-sectional imaging (MRI and/or $\mathrm{CT})$.

\section{Discussion}

In the field of senology, there were different trends during the last decade, that significantly changed therapy algorithms. On the one hand, there is a trend towards de-escalation of surgical and systemic therapy. Axillary lymph node dissection could mostly be replaced by sentinel node biopsy and breastconserving surgery could prove a comparable outcome to radical mastectomy. Consequently, therapeutic side effects were reduced drastically $[13,25]$. In terms of systemic therapy multigene assays helped individualize the therapeutic approach and to reduce the application of adjuvant chemotherapies [2628].

On the other hand, there is a trend to escalate systemic therapy for $\mathrm{BC}$ patients at high risk. In addition, to the classic pathologic and molecular pathologic risk factors the response to neoadjuvant therapy plays a decisive role in identifying patients with a high risk of relapse. BC patients, who achieve complete pathological response during neoadjuvant therapy, seem to have the best clinical outcome. This could be demonstrated especially for triple negative tumors [29]. Patients with residual tumor after neoadjuvant therapy are however at high risk of tumor relapse. This subgroup can benefit from an escalation of cancer therapy by applying post-NAC. The positive clinical effect of the post-NAC could be displayed for the Her2 positive and the triple negative breast cancer. For the hormone receptor positive breast cancer, there are promising results [21-23]. Another escalation of cancer therapy was applied to patients with BRCA mutations, who received Olaparib in the OLYMPIA study in the post-neoadjuvant setting. The PARP inhibition could demonstrate highly beneficial clinical effects [30].

The evaluation of the clinical response to NAC in the mammary gland can be achieved by pathological examination of the tumor bed after breast conserving therapy [21]. The assessment of the response of the axillary, respectively tumor-infiltrated lymph nodes, without performing a complete axillary dissection with its additional side effects is technically challenging.

One of the reasons for this is the fact, that the same suspicious lymph nodes have to be analyzed before and after their alteration caused by NAC [19, 31, 32]. The evolving role of Marked Lymph Node Biopsy (MLNB) and Targeted Axillary Dissection (TAD) enables the option of analyzing the effect of NAC. Hence, a statement whether tumor-infiltrated lymph nodes turned negative during therapy can be made [31, 33]. 
Both mammary and axillary tumor manifestations can develop differently. Because of this, the individual assessment of each of these two tumor-localities is crucial [34]. The identification of chemotherapy resistant tumor manifestations provides the option of offering post-NAC-therapy to selected BC-patients [35].

Up to now, the combination of mammography and sonography is the standard of care concerning morphological imaging for BC-detection [36]. Especially the evaluation of the dignity of lymph nodes is prone to errors. Sonography as the standard technique for lymph node evaluation varies from 15.00 to $85.00 \%$ in terms of sensitivity. The specificity however is stated to be about 90.00 to $95.00 \%$ depending on the literature $[6,37,38]$. We therefore focused on the sensitivity of different medical imaging procedures: sonography, mammography, MRI and CT and aimed to analyze which technique could improve sensitivity in terms of the detection of tumor-infiltrated lymph nodes. Furthermore, we compared "conventional imaging" consisting of sonography and mammography to cross-sectional imaging consisting of MRI and CT.

Neoadjuvant systemic therapy is becoming increasingly important for treatment of BC worldwide. In addition, tumor-infiltrated lymph nodes often become tumor-free after the application of such neoadjuvant therapy. Due to this, we conducted a retrospective analysis and excluded patients with NAC. However, a prospective analysis comparing different imaging techniques for the detection of axillary lymph nodes while excluding patients with neoadjuvant therapies would be highly interesting.

Yet, such a study would be challenging concerning implementation and patient recruitment. For our analysis we included patients with pathologically confirmed infiltration of axillary lymph nodes.

The analysis of our data showed a sensitivity of $34.56 \%$ for sonography and $36.11 \%$ for the combination of sonography and mammography for the detection of tumor-infiltrated lymph nodes in the axilla. Our results are within the expected range. It is however noticeable that sensitivity for sonography is reported to vary from 15.00 to $85.00 \%[5,6,37,38]$. Elastography may improve sensitivity in this context $[39,40]$. In our study mammography showed a relatively low sensitivity of $14.60 \%$ for the detection tumor-infiltrated lymph nodes. The reason for this lies in the insufficient depiction of the axilla by this technique and is comparable to previous results which analyzed a sensitivity of $13.00 \%$ [5].

For the MRI analysis, we could detect a sensitivity of $41.51 \%$ and $63.83 \%$ for cross-sectional imaging as a combination of MRI and CT. The diagnostic reliability of MRI for the evaluation of axillary nodal staging in $\mathrm{BC}$ reported by previous studies shows inconsistent results. This inconsistency is caused by the monocentric character of many studies, differing MRI examination-technology as well as instruments or varying patient inclusion criteria [10-12, 41]. Additionally, in the past, MRI for non-palpable lymph nodes was mostly not focused on the detection of axillary lymph node metastasis in patients with BC. Instead, the reason for an additional MRI was inter alia dense breast tissue or invasive lobular mammary carcinoma $[24,42]$. 
Computed tomography is established for staging exams in wake of $\mathrm{BC}$ rather than screening or diagnostic of a mammary tumor itself. The specificity is reported to be about $40.00 \%$ [43]. In our study we could analyze a sensitivity of $51.40 \%$ for the detection of infiltrated lymph nodes for patients who received a CT as staging examination. This sensitivity is slightly lower than reported in the literature [44]. However, it has to be considered that the focus of this diagnostic was the detection of distant metastasis [44]. In this field, research approaches compared the CT results before and after chemotherapy to evaluate the response in axillary lymph nodes. This investigation could demonstrate promising results [45].

The combination of advancing MRI technology and CT staging, both focusing on axillary lymph nodes, could possibly improve sensitivity in the future. As CT examinations of the chest and the abdomen are the standard staging procedure for BC patients, this imaging data is already available [17]. During the period of data collection, we could detect an increasing importance of the cross-sectional imaging.

The combination of all four imaging modalities reaches a sensitivity of $68.89 \%$. The combined evaluation of the results as presented in table 5 depicts clearly that cross-sectional imaging contributes significantly to the increase in sensitivity and underlines its importance.

The regression analysis in table 6 for evaluating the influence of various clinical parameters on the sensitivity reveals that tumor size, grading and the number of tumor-infiltrated lymph nodes significantly influences the sensitivity of imaging techniques. Large tumor spread, aggressive BC subtypes and heavily tumor-infiltrated axillary lymph nodes lead to a higher probability of being detected correctly. Table 7 illustrates that especially for tumors, smaller than $2 \mathrm{~cm}$ (pT1), MRI is the best imaging. Moreover, crosssectional imaging significantly improves the sensitivity for the detection of infiltrated lymph nodes in relation to conventional imaging for the subgroup of BC patients with $\mathrm{pT} 1$ tumors. Whereas $\mathrm{CT}$, mammography and sonography show significantly lower sensitivity values for the detection of tumorinfiltrated lymph nodes for smaller breast tumors than for patients with large tumor spread. Especially pT1 tumors with high grading are however at high risk of developing lymph node metastasis. Especially for this subgroup of BC patients carrying out an MRI could be valuable [46].

For other clinical parameters such as age, intrinsic subtype, histological subtype and body mass index [BMI] we could not prove any effect of image modality on the sensitivity of lymph node detection.

One of the main limitations of this analysis is the retrospective data collection. The quality of the study could be improved, if all patients had received all four imaging modalities with focus on axillary infiltration of lymph nodes. Furthermore, the assessment of each imaging technique by the same diagnostician would have reduced interobserver variability.

Despite these limitations, we could demonstrate that cross-sectional imaging as MRI and CT in combination with MRI can improve the diagnostic performance for detecting tumor-infiltrated lymph nodes of BC-patients. Current literature reports that MRI outperforms mammography and ultrasound for the detection of early breast cancer. 
Moreover, it reduces the exposure to radiation as well as the potentially painful compression of the patient's breast during the imaging process [47]. Therefore, the increasing use of MRI technology for BC patients could help to detect tumors at an earlier stage and help to identify tumor-infiltrated axillary lymph nodes. The additional focus of CT imaging on axillary lymph nodes could even improve this trend. This could enable the use of technologies such as the Marked Lymph Node Biopsy (MLNB) and Targeted Axillary Dissection (TAD). Consequently, patients at high risk, who did not achieve complete remission during NAC, could receive treatment with post-neoadjuvant therapeutic strategies. Currently, some of these critical patients can be deprived of a post-neoadjuvant treatment if tumor-infiltrated lymph nodes in the axilla are not detected at the beginning of cancer therapy.

\section{Conclusion}

In summary, we could demonstrate that cross-sectional imaging with MRI and CT can improve the sensitivity for detecting tumor infiltrated axillary lymph nodes in $\mathrm{BC}$ patients. The increasing importance of NAC and post-NAC therapeutic algorithms in the treatment of BC makes the reliable detection and marking of tumor-infested lymph nodes pivotal. Only the successful detection of a tumor-infiltrated lymph node at the time of diagnosis allows the evaluation of the response to NAC, thus allowing access to prognosis-improving post-neoadjuvant therapies.

\section{Declarations}

Funding: This study was not funded.

Conflicts of interest/Competing interest: The authors declare that they have no conflict of interest.

Availability of data and material: The data that support the findings of this study are available from Joachim Diessner but restrictions apply to the availability of these data, which were used under license for the current study, and so are not publicly available. Data are however available from the authors upon reasonable request and with permission of Joachim Diessner.

Authors' contributions: All authors contributed to the study conception and design. Material preparation, data collection and analysis were performed by Laura Anders. The first draft of the manuscript was written by Joachim Diessner and all authors commented on previous versions of the manuscript. All authors read and approved the final manuscript.

Ethics approval: Ethical approval was waived by the local Ethics Committee of University of Wuerzburg in view of the retrospective nature of the study and all the procedures being performed were part of the routine care. (No. 20200417 01)

Consent for publication: all authors read and approved the final manuscript

\section{References}


1.Carter CL, Allen C, Henson DE: Relation of tumor size, lymph node status, and survival in 24,740 breast cancer cases. Cancer 1989, 63(1):181-187.

2.de Boer M, van Dijck JA, Bult P, Borm GF, Tjan-Heijnen VC: Breast cancer prognosis and occult lymph node metastases, isolated tumor cells, and micrometastases. J Natl Cancer Inst 2010, 102(6):410-425.

3.Rao R, Euhus D, Mayo HG, Balch C: Axillary node interventions in breast cancer: a systematic review. JAMA 2013, 310(13):1385-1394.

4.Choi HY, Park M, Seo M, Song E, Shin SY, Sohn YM: Preoperative Axillary Lymph Node Evaluation in Breast Cancer: Current Issues and Literature Review. Ultrasound Q 2017, 33(1):6-14.

5.Valente SA, Levine GM, Silverstein MJ, Rayhanabad JA, Weng-Grumley JG, Ji L, Holmes DR, Sposto R, Sener SF: Accuracy of predicting axillary lymph node positivity by physical examination, mammography, ultrasonography, and magnetic resonance imaging. Ann Surg Oncol 2012, 19(6):1825-1830.

6.Alvarez S, Anorbe E, Alcorta P, Lopez F, Alonso I, Cortes J: Role of sonography in the diagnosis of axillary lymph node metastases in breast cancer: a systematic review. AJR Am J Roentgenol 2006, 186(5):1342-1348.

7.Lee SC, Jain PA, Jethwa SC, Tripathy D, Yamashita MW: Radiologist's role in breast cancer staging: providing key information for clinicians. Radiographics 2014, 34(2):330-342.

8.Kutomi G, Ohmura T, Satomi F, Takamaru T, Shima H, Suzuki Y, Otokozawa S, Zembutsu H, Mori M, Hirata K: Lymph node shape in computed tomography imaging as a predictor for axillary lymph node metastasis in patients with breast cancer. Exp Ther Med 2014, 8(2):681-685.

9.Uematsu T, Sano M, Homma K: In vitro high-resolution helical CT of small axillary lymph nodes in patients with breast cancer: correlation of CT and histology. AJR Am J Roentgenol 2001, 176(4):10691074.

10.Kuijs VJ, Moossdorff M, Schipper RJ, Beets-Tan RG, Heuts EM, Keymeulen KB, Smidt ML, Lobbes MB: The role of MRI in axillary lymph node imaging in breast cancer patients: a systematic review. Insights Imaging 2015, 6(2):203-215.

11.Al-Hattali S, Vinnicombe SJ, Gowdh NM, Evans A, Armstrong S, Adamson D, Purdie CA, Macaskill EJ: Breast MRI and tumour biology predict axillary lymph node response to neoadjuvant chemotherapy for breast cancer. Cancer Imaging 2019, 19(1):91.

12.Zhou P, Wei Y, Chen G, Guo L, Yan D, Wang Y: Axillary lymph node metastasis detection by magnetic resonance imaging in patients with breast cancer: A meta-analysis. Thorac Cancer 2018, 9(8):989-996.

13.de Meric de Bellefon M, Lemanski C, Ducteil A, Fenoglietto P, Azria D, Bourgier C: Management of the Axilla in the Era of Breast Cancer Heterogeneity. Front Oncol 2018, 8:84. 
14.Donker M, van Tienhoven G, Straver ME, Meijnen P, van de Velde CJ, Mansel RE, Cataliotti L, Westenberg $\mathrm{AH}$, Klinkenbijl JH, Orzalesi L et al: Radiotherapy or surgery of the axilla after a positive sentinel node in breast cancer (EORTC 10981-22023 AMAROS): a randomised, multicentre, open-label, phase 3 non-inferiority trial. Lancet Oncol 2014, 15(12):1303-1310.

15.Giuliano AE, Hunt KK, Ballman KV, Beitsch PD, Whitworth PW, Blumencranz PW, Leitch AM, Saha S, McCall LM, Morrow M: Axillary dissection vs no axillary dissection in women with invasive breast cancer and sentinel node metastasis: a randomized clinical trial. JAMA 2011, 305(6):569-575.

16.Shirzadi A, Mahmoodzadeh H, Qorbani M: Assessment of sentinel lymph node biopsy after neoadjuvant chemotherapy for breast cancer in two subgroups: Initially node negative and node positive converted to node negative - A systemic review and meta-analysis. J Res Med Sci 2019, 24:18.

17.Ditsch N, Untch M, Kolberg-Liedtke C, Jackisch C, Krug D, Friedrich M, Janni W, Muller V, Albert US, Banys-Paluchowski M et al: AGO Recommendations for the Diagnosis and Treatment of Patients with Locally Advanced and Metastatic Breast Cancer: Update 2020. Breast Care (Basel) 2020, 15(3):294-309.

18.Boughey JC, Suman VJ, Mittendorf EA, Ahrendt GM, Wilke LG, Taback B, Leitch AM, Kuerer HM, Bowling M, Flippo-Morton TS et al: Sentinel lymph node surgery after neoadjuvant chemotherapy in patients with node-positive breast cancer: the ACOSOG Z1071 (Alliance) clinical trial. JAMA 2013, 310(14):1455-1461.

19.Caudle AS, Yang WT, Krishnamurthy S, Mittendorf EA, Black DM, Gilcrease MZ, Bedrosian I, Hobbs BP, DeSnyder SM, Hwang RF et al: Improved Axillary Evaluation Following Neoadjuvant Therapy for Patients With Node-Positive Breast Cancer Using Selective Evaluation of Clipped Nodes: Implementation of Targeted Axillary Dissection. J Clin Oncol 2016, 34(10):1072-1078.

20.Veronesi U, Paganelli G, Viale G, Luini A, Zurrida S, Galimberti V, Intra M, Veronesi P, Robertson C, Maisonneuve $\mathrm{P}$ et al: A randomized comparison of sentinel-node biopsy with routine axillary dissection in breast cancer. N Engl J Med 2003, 349(6):546-553.

21.von Minckwitz G, Huang CS, Mano MS, Loibl S, Mamounas EP, Untch M, Wolmark N, Rastogi P, Schneeweiss A, Redondo A et al: Trastuzumab Emtansine for Residual Invasive HER2-Positive Breast Cancer. N Engl J Med 2019, 380(7):617-628.

22.Masuda N, Lee SJ, Ohtani S, Im YH, Lee ES, Yokota I, Kuroi K, Im SA, Park BW, Kim SB et al: Adjuvant Capecitabine for Breast Cancer after Preoperative Chemotherapy. N Engl J Med 2017, 376(22):21472159.

23.Johnston SRD, Harbeck N, Hegg R, Toi M, Martin M, Shao ZM, Zhang QY, Martinez Rodriguez JL, Campone M, Hamilton E et al: Abemaciclib Combined With Endocrine Therapy for the Adjuvant Treatment of HR+, HER2-, Node-Positive, High-Risk, Early Breast Cancer (monarchE). J Clin Oncol 2020, 38(34):3987-3998. 
24.Bakker MF, de Lange SV, Pijnappel RM, Mann RM, Peeters PHM, Monninkhof EM, Emaus MJ, Loo CE, Bisschops RHC, Lobbes MBI et al: Supplemental MRI Screening for Women with Extremely Dense Breast Tissue. N Engl J Med 2019, 381(22):2091-2102.

25.Veronesi U, Cascinelli N, Mariani L, Greco M, Saccozzi R, Luini A, Aguilar M, Marubini E: Twenty-year follow-up of a randomized study comparing breast-conserving surgery with radical mastectomy for early breast cancer. N Engl J Med 2002, 347(16):1227-1232.

26.van der Voort A, van Ramshorst MS, van Werkhoven ED, Mandjes IA, Kemper I, Vulink AJ, Oving IM, Honkoop AH, Tick LW, van de Wouw AJ et al: Three-Year Follow-up of Neoadjuvant Chemotherapy With or Without Anthracyclines in the Presence of Dual ERBB2 Blockade in Patients With ERBB2-Positive Breast Cancer: A Secondary Analysis of the TRAIN-2 Randomized, Phase 3 Trial. JAMA Oncol 2021.

27.Tolaney SM, Barry WT, Dang CT, Yardley DA, Moy B, Marcom PK, Albain KS, Rugo HS, Ellis M, Shapira I et al: Adjuvant paclitaxel and trastuzumab for node-negative, HER2-positive breast cancer. N Engl J Med 2015, 372(2):134-141.

28.Mariotto A, Jayasekerea J, Petkov V, Schechter CB, Enewold L, Helzlsouer KJ, Feuer EJ, Mandelblatt JS: Expected Monetary Impact of Oncotype DX Score-Concordant Systemic Breast Cancer Therapy Based on the TAILORx Trial. J Natl Cancer Inst 2020, 112(2):154-160.

29.Huang M, O’Shaughnessy J, Zhao J, Haiderali A, Cortes J, Ramsey SD, Briggs A, Hu P, Karantza V, Aktan G et al: Association of Pathologic Complete Response with Long-Term Survival Outcomes in TripleNegative Breast Cancer: A Meta-Analysis. Cancer Res 2020, 80(24):5427-5434.

30.Tutt ANJ, Garber JE, Kaufman B, Viale G, Fumagalli D, Rastogi P, Gelber RD, de Azambuja E, Fielding A, Balmana J et al: Adjuvant Olaparib for Patients with BRCA1- or BRCA2-Mutated Breast Cancer. N Engl J Med 2021.

31.Swarnkar PK, Tayeh S, Michell MJ, Mokbel K: The Evolving Role of Marked Lymph Node Biopsy (MLNB) and Targeted Axillary Dissection (TAD) after Neoadjuvant Chemotherapy (NACT) for NodePositive Breast Cancer: Systematic Review and Pooled Analysis. Cancers (Basel) 2021, 13(7).

32.Simons JM, Koppert LB, Luiten EJT, van der Pol CC, Samiei S, de Wilt JHW, Siesling S, Smidt ML: Deescalation of axillary surgery in breast cancer patients treated in the neoadjuvant setting: a Dutch population-based study. Breast Cancer Res Treat 2020, 180(3):725-733.

33.Flores-Funes D, Aguilar-Jimenez J, Martinez-Galvez M, Ibanez-lbanez MJ, Carrasco-Gonzalez L, GilIzquierdo Jl, Aguayo-Albasini JL: The problem of axillary staging in breast cancer after neoadjuvant chemotherapy. Role of targeted axillary dissection and types of lymph node markers. Cir Esp (Engl Ed) 2020, 98(9):510-515. 
34.Choi HJ, Ryu JM, Kim I, Nam SJ, Kim SW, Yu J, Lee JE, Lee SK: Prediction of axillary pathologic response with breast pathologic complete response after neoadjuvant chemotherapy. Breast Cancer Res Treat 2019, 176(3):591-596.

35.Caparica R, Lambertini M, Ponde N, Fumagalli D, de Azambuja E, Piccart M: Post-neoadjuvant treatment and the management of residual disease in breast cancer: state of the art and perspectives. Ther Adv Med Oncol 2019, 11:1758835919827714.

36.Okello J, Kisembo H, Bugeza S, Galukande M: Breast cancer detection using sonography in women with mammographically dense breasts. BMC Med Imaging 2014, 14:41.

37.Rezvani A, Zahergivar A, Iranpour P, Akrami M, Kazemi S: Diagnostic Accuracy of Axillary Ultrasonography Compared with Intra-operative Pathological Findings in Patients with Breast Cancer. Asian Pac J Cancer Prev 2018, 19(12):3615-3621.

38.Riedel F, Schaefgen B, Sinn HP, Feisst M, Hennigs A, Hug S, Binnig A, Gomez C, Harcos A, Stieber A et al: Diagnostic accuracy of axillary staging by ultrasound in early breast cancer patients. Eur J Radiol 2021, 135:109468.

39.Tsai WC, Lin CK, Wei HK, Yu BL, Hung CF, Cheng SH, Chen CM: Sonographic elastography improves the sensitivity and specificity of axilla sampling in breast cancer: a prospective study. Ultrasound Med Biol 2013, 39(6):941-949.

40.Chang W, Jia W, Shi J, Yuan C, Zhang Y, Chen M: Role of Elastography in Axillary Examination of Patients With Breast Cancer. J Ultrasound Med 2018, 37(3):699-707.

41.Luo N, Su D, Jin G, Liu L, Zhu X, Xie D, Liu Y: Apparent diffusion coefficient ratio between axillary lymph node with primary tumor to detect nodal metastasis in breast cancer patients. J Magn Reson Imaging 2013, 38(4):824-828.

42.Baltzer PA, Dietzel M, Burmeister HP, Zoubi R, Gajda M, Camara O, Kaiser WA: Application of MR mammography beyond local staging: is there a potential to accurately assess axillary lymph nodes? evaluation of an extended protocol in an initial prospective study. AJR Am J Roentgenol 2011, 196(5):W641-647.

43.Marino MA, Avendano D, Zapata P, Riedl CC, Pinker K: Lymph Node Imaging in Patients with Primary Breast Cancer: Concurrent Diagnostic Tools. Oncologist 2020, 25(2):e231-e242.

44. Yuen S, Yamada K, Goto M, Sawai K, Nishimura T: CT-based evaluation of axillary sentinel lymph node status in breast cancer: value of added contrast-enhanced study. Acta Radiol 2004, 45(7):730-737.

45.Wang L, Li Y, Li J, Wang T, Xie Y, He Y, Fan Z, Ouyang T: Computed tomography reconstruction for evaluating response in axillary lymph nodes of breast cancer after neoadjuvant chemotherapy. Clin Transl Oncol 2021, 23(2):240-245. 
46.Zhao YX, Liu YR, Xie S, Jiang YZ, Shao ZM: A Nomogram Predicting Lymph Node Metastasis in T1 Breast Cancer based on the Surveillance, Epidemiology, and End Results Program. J Cancer 2019, 10(11):2443-2449.

47.Mann RM, Kuhl CK, Moy L: Contrast-enhanced MRI for breast cancer screening. J Magn Reson Imaging 2019, 50(2):377-390.

\section{Tables}

Table 1: Basic characteristics of the study population.

\begin{tabular}{|c|c|c|c|}
\hline & & number & percent \\
\hline \multirow{4}{*}{$\begin{array}{l}\text { age } \\
\text { (in years) }\end{array}$} & $20-39$ & 20 & $5.24 \%$ \\
\hline & $40-59$ & 144 & $37.70 \%$ \\
\hline & $60-79$ & 177 & $46.34 \%$ \\
\hline & $>79$ & 41 & $10.73 \%$ \\
\hline \multirow[t]{2}{*}{ sex } & female & 378 & $98.95 \%$ \\
\hline & male & 4 & $1.05 \%$ \\
\hline \multirow[t]{3}{*}{ menopausal status } & premenopausal & 67 & $17.72 \%$ \\
\hline & perimenopausal & 22 & $5.82 \%$ \\
\hline & postmenopausal & 289 & $76.46 \%$ \\
\hline \multirow{7}{*}{$\begin{array}{l}\text { body mass index } \\
\text { (in } \mathrm{kg} / \mathrm{m}^{2} \text { ) }\end{array}$} & $<18,5$ & 7 & $1.83 \%$ \\
\hline & $18,5-24,9$ & 165 & $43.19 \%$ \\
\hline & $25-29,9$ & 110 & $28.79 \%$ \\
\hline & $30-34,9$ & 63 & $16.49 \%$ \\
\hline & $35-39,9$ & 19 & $4.97 \%$ \\
\hline & $>40$ & 15 & $3.93 \%$ \\
\hline & missing values & 3 & $0.79 \%$ \\
\hline
\end{tabular}

Table 2: Stage and subtype of breast cancer. 


\begin{tabular}{|c|c|c|c|}
\hline & & number & percent \\
\hline \multirow[t]{6}{*}{ intrinsic subtype } & luminal $A$ & 220 & $57.59 \%$ \\
\hline & luminal B, Her2 neg & 91 & $23.82 \%$ \\
\hline & luminal B, Her2 pos & 35 & $9.16 \%$ \\
\hline & Her2 overexpressing & 11 & $2.88 \%$ \\
\hline & triple negative & 23 & $6.02 \%$ \\
\hline & unknown & 2 & $0.52 \%$ \\
\hline \multirow{4}{*}{$\begin{array}{l}\text { Ki67 } \\
\text { (in \%) }\end{array}$} & $0-25$ & 237 & $62.86 \%$ \\
\hline & $26-50$ & 92 & $24.40 \%$ \\
\hline & $51-75$ & 31 & $8.22 \%$ \\
\hline & $76-100$ & 17 & $4.51 \%$ \\
\hline \multirow[t]{3}{*}{ grading } & 1 & 23 & $6.05 \%$ \\
\hline & 2 & 254 & $66.84 \%$ \\
\hline & 3 & 103 & $27.11 \%$ \\
\hline \multirow[t]{5}{*}{ pathological tumor size using the TNM system } & 1 & 131 & $34.29 \%$ \\
\hline & 2 & 169 & $44.24 \%$ \\
\hline & 3 & 44 & $11.52 \%$ \\
\hline & 4 & 33 & $8.64 \%$ \\
\hline & unknown & 5 & $1.31 \%$ \\
\hline \multirow[t]{3}{*}{ lymph node status using the TNM system } & 1 & 266 & $69.63 \%$ \\
\hline & 2 & 69 & $18.06 \%$ \\
\hline & 3 & 47 & $12.30 \%$ \\
\hline \multirow[t]{2}{*}{ metastasis } & no & 344 & $90.05 \%$ \\
\hline & yes & 38 & $9.95 \%$ \\
\hline
\end{tabular}

Table 3: Imaging modalities during the investigated period. 


\begin{tabular}{|lllllllll|}
\hline & 2014 & 2015 & 2016 & 2017 & 2018 & 2019 & 2020 & all \\
\hline $\begin{array}{l}\text { conventional imaging (Cl; } \\
\begin{array}{l}\text { sonography and/or } \\
\text { mammography) }\end{array}\end{array}$ & 66 & 43 & 52 & 58 & 56 & 64 & 43 & 382 \\
$\begin{array}{l}\text { cross-sectional imaging (SCl: MRI } \\
\text { and/or CT) }\end{array}$ & 16 & 14 & 19 & 31 & 38 & 52 & 31 & 201 \\
\hline ratio SCl/SI & 0.24 & 0.33 & 0.37 & 0.53 & 0.68 & 0.81 & 0.72 & 0.53 \\
\hline
\end{tabular}

Table 4: Results of the Spearman-rho test of the different imaging modalities.

\begin{tabular}{|c|c|c|c|c|}
\hline Spearman-Rho & & sonography & mammography & MRI \\
\hline \multirow[t]{3}{*}{ sonography } & correlation coefficient & 1 & 0.416 & 0.347 \\
\hline & $\mathrm{p}$ (2-sided) & . & 0.000 & 0.000 \\
\hline & number & 379 & 360 & 106 \\
\hline \multirow[t]{3}{*}{ mammography } & correlation coefficient & 0.416 & 1 & 0.257 \\
\hline & $\mathrm{p}$ (2-sided) & 0.000 & & 0.010 \\
\hline & number & 360 & 363 & 99 \\
\hline \multirow[t]{3}{*}{ MRI } & correlation coefficient & 0.347 & 0.257 & 1 \\
\hline & $\mathrm{p}$ (2-sided) & 0.000 & 0.010 & . \\
\hline & number & 106 & 99 & 106 \\
\hline \multirow[t]{3}{*}{ CT } & correlation coefficient & 0.549 & 0.262 & 0.427 \\
\hline & $\mathrm{p}$ (2-sided) & 0.000 & 0.002 & 0.003 \\
\hline & number & 140 & 139 & 47 \\
\hline
\end{tabular}

Table 5: Sensitivity of the different imaging modalities. 


\begin{tabular}{|c|c|c|c|c|}
\hline & $\begin{array}{l}\text { negative nodal status in at } \\
\text { least one imaging modality }\end{array}$ & $\begin{array}{l}\text { positive nodal status in at } \\
\text { least one imaging modality }\end{array}$ & all & $\begin{array}{l}\text { sensitivity } \\
\text { in percent } \\
(\%)\end{array}$ \\
\hline $\begin{array}{l}\text { all imaging } \\
\text { modalities }\end{array}$ & 14 & 31 & 45 & 68.89 \\
\hline $\begin{array}{l}\text { sonography, MRI } \\
\text { and CT }\end{array}$ & 15 & 32 & 47 & 68.09 \\
\hline $\begin{array}{l}\text { mammography, } \\
\text { MRI and CT }\end{array}$ & 15 & 29 & 44 & 65.91 \\
\hline MRI and CT & 17 & 30 & 47 & 63.83 \\
\hline $\begin{array}{l}\text { sonography, } \\
\text { mammography } \\
\text { and CT }\end{array}$ & 54 & 83 & 137 & 60.58 \\
\hline $\begin{array}{l}\text { sonography and } \\
\text { CT }\end{array}$ & 58 & 82 & 140 & 58.57 \\
\hline $\begin{array}{l}\text { mammography } \\
\text { and CT }\end{array}$ & 61 & 78 & 139 & 56.12 \\
\hline $\begin{array}{l}\text { sonography and } \\
\text { MRI }\end{array}$ & 50 & 56 & 106 & 52.83 \\
\hline CT & 69 & 73 & 142 & 51.40 \\
\hline $\begin{array}{l}\text { sonography, } \\
\text { mammography } \\
\text { and MRI }\end{array}$ & 49 & 50 & 99 & 50.51 \\
\hline $\begin{array}{l}\text { mammography } \\
\text { and MRI }\end{array}$ & 55 & 45 & 100 & 45.00 \\
\hline MRI & 62 & 44 & 106 & 41.51 \\
\hline $\begin{array}{l}\text { sonography and } \\
\text { mammography }\end{array}$ & 230 & 130 & 360 & 36.11 \\
\hline sonography & 248 & 131 & 379 & 34.56 \\
\hline mammography & 310 & 53 & 363 & 14.60 \\
\hline
\end{tabular}

Table 6: Multiple binary logistic regression analysis of variables influencing the detection of positive lymph nodes. Tested variables were age, body mass index, subtypes of $B C$, grading, stage of tumor size and nodal status according to the TNM guidelines, metastasis and histological type of BC. 


\begin{tabular}{|c|c|c|c|}
\hline \multirow[t]{2}{*}{ Imaging modalities } & \multirow[t]{2}{*}{ variables } & Odds ratio & \multirow[t]{2}{*}{$\mathrm{p}$} \\
\hline & & $\begin{array}{l}\text { (95\% confidence } \\
\text { interval) }\end{array}$ & \\
\hline \multirow[t]{3}{*}{ all (anyone of all) } & tumor size & $1.93(1.43-2.59)$ & 0.000 \\
\hline & $\begin{array}{l}\text { nodal } \\
\text { status }\end{array}$ & $1.66(1.17-2.36)$ & 0.005 \\
\hline & grading & $2.52(1.49-4.30)$ & 0.001 \\
\hline \multirow[t]{2}{*}{ Cross-sectional imaging (MRI and/or CT) } & $\begin{array}{l}\text { nodal } \\
\text { status }\end{array}$ & $2.03(1.25-3.30)$ & 0.004 \\
\hline & grading & $3.29(1.49-7.24)$ & 0.003 \\
\hline \multirow{3}{*}{$\begin{array}{l}\text { Conventional imaging (sonography and/or } \\
\text { mammography) }\end{array}$} & tumor size & $1.60(1.20-2.14)$ & 0.001 \\
\hline & $\begin{array}{l}\text { nodal } \\
\text { status }\end{array}$ & $1.56(1.10-2.20)$ & 0.011 \\
\hline & grading & $2.98(1.72-5.16)$ & 0.000 \\
\hline \multirow[t]{3}{*}{ sonography } & tumor size & $1.53(1.14-2.04)$ & 0.004 \\
\hline & $\begin{array}{l}\text { nodal } \\
\text { status }\end{array}$ & $1.62(1.15-2.29)$ & 0.006 \\
\hline & grading & $3.05(1.75-5.32)$ & 0.000 \\
\hline \multirow[t]{2}{*}{ mammography } & tumor size & $1.93(1.33-2.80)$ & 0.001 \\
\hline & grading & $2.72(1.33-5.55)$ & 0.006 \\
\hline \multirow[t]{2}{*}{ MRI } & $\begin{array}{l}\text { nodal } \\
\text { status }\end{array}$ & $3.45(1.58-7.52)$ & 0.002 \\
\hline & grading & $4.22(1.31-13.65)$ & 0.016 \\
\hline CT & grading & $3.43(1.33-8.87)$ & 0.011 \\
\hline
\end{tabular}

Table 7: Sensitivity of the different imaging modalities depending on tumor size. 


\begin{tabular}{|lcccc|}
\hline sensitivity in percent (\%) & T1 & T2 & T3 & T4 \\
\hline at least one positive lymph node in any imaging & 24.48 & 46.02 & 70.21 & 72.22 \\
\hline MRI and/or CT & 36.51 & 52.81 & 61.76 & 62.96 \\
\hline sonography and/or mammography & 20.28 & 40.34 & 57.45 & 58.33 \\
\hline sonography & 18.88 & 38.86 & 51.11 & 55.88 \\
\hline mammography & 5.84 & 14.46 & 24.44 & 38.24 \\
\hline MRI & 41.46 & 40.48 & 52.94 & 50 \\
\hline CT & 30.77 & 56.06 & 52 & 60.87 \\
\hline
\end{tabular}

